\begin{abstract}
Introduction: Casein phosphopeptide-amorphous calcium phosphate (CPP-ACP) and $\underline{\mathrm{CPP}-\mathrm{ACP}}$ with fluoride (CPP-ACFP) have been shown to provide bioavailable ions to promote mineralization. Hence, the aim of this study was to evaluate the materials' biocompatibility and osteogenic/calcification potential for endodontic applications.
\end{abstract}

Methods: Human and mouse osteoblast-like and fibroblast-like cell lines were incubated with $0.05 \%$ to $3.0 \%$ w/v CPP-ACP and CPP-ACFP and toxicity, proliferation, alkaline phosphatase (ALP), IL-1 $\alpha$ and IL-6 production, collagen type I, osteocalcin and osteopontin production and mineralization/calcification were determined.

Results: CPP-ACP and CPP-ACFP were non-toxic and had no significant effect on proliferation or production of the inflammatory cytokine IL-1 $\alpha$. ALP activity of the osteoblast-like cells was significantly $(P<0.05)$ increased by CPP-ACP and CPPACFP, as was the production of the osteotropic cytokine IL-6, the formation of calcium mineral deposits and the secretion of mineralization-related proteins (collagen type I and osteocalcin).

Conclusions: CPP-ACP and CPP-ACFP are biocompatible and have the potential to induce osteoblastic differentiation and mineralization. Potential applications include apexification, perforation repair, vital pulp therapy and regenerative endodontic procedures. 
Keywords: CPP-ACP, CPP-ACFP, endodontics, biocompatibility, proliferation, differentiation 


\section{Introduction}

The mechanism of action of endodontic repair cements based on calcium hydroxide and calcium silicate, such as mineral trioxide aggregate (MTA), depends on their bioactivity represented by their ability to release ions, such as calcium $\left(\mathrm{Ca}^{2+}\right)$ and hydroxide $\left(\mathrm{OH}^{-}\right)$. Calcium silicate-based cements that release $\mathrm{Ca}^{2+}$ enhance hard tissue-forming cell viability, proliferation and differentiation and the $\mathrm{OH}^{-}$release increases the alkalinity of the environment which supports hard tissue repair and active calcification $(1,2)$. Released $\mathrm{Ca}^{2+}$ from endodontic repair cements stimulates the expression of mineralization-associated genes such as bone morphogenetic protein-2, collagen 1 and osteocalcin (3-5). The release of high concentrations of $\mathrm{Ca}^{2+}$ from the repair cement at the pulpal site activates the migration of pre-odontoblasts located in the central pulp $(6,7) \cdot \mathrm{Ca}^{2+}$ released from repair cements may serve as a bioactive signal that promotes the process of cell-based tissue repair. However, the high $\mathrm{pH}$ of calcium hydroxide may not be optimal for cell-based repair mechanisms, and modification of cements to improve their physical and biological properties show promising results (2).

Casein phosphopeptide-amorphous calcium phosphate (CPP-ACP) is a phosphopeptide stabilized $\mathrm{Ca}^{2+}$ and phosphate ion $\left(\mathrm{P}_{i}\right)$ complex which provides bioavailable $\mathrm{Ca}^{2+}$ at neutral $\mathrm{pH}$ and promotes remineralization of enamel and dentin (8). A fluoride-containing version (CPP-ACFP; casein phosphopeptide-amorphous calcium fluoride phosphate) has superior remineralizing efficacy compared with CPP$\mathrm{ACP}$ (9). In vitro, calcium-enriched CPP induced $\mathrm{Ca}^{2+}$ uptake by osteoblast-like cells, promoted osteoblastic differentiation, increased the level and activity of alkaline phosphatase (ALP) and enhanced the formation of calcified nodules $(10,11)$. CPPACP therefore may play a role in promoting osteogenesis and calcification. 
Furthermore, the addition of CPP-ACP to calcium silicate-based cements has been

\section{Materials and Methods}

\section{Cell culture}

Human (MG-63) and mouse (MC3T3-E1) osteoblast-like cell lines (Sigma-Aldrich, NSW, Australia), and human (HGF-1) and mouse (NIH3T3) fibroblast-like cell lines (ATCC, VA, USA) were cultured in complete Alpha Minimum Essential Medium (complete $\alpha$-MEM), composed of $\alpha$-MEM supplemented with $10 \% \mathrm{v} / \mathrm{v}$ foetal calf serum (FCS), $1 \mathrm{U} / \mathrm{ml}$ penicillin, $0.1 \mathrm{mg} / \mathrm{ml}$ streptomycin, $1 \mathrm{mM}$ sodium pyruvate and $2 \mathrm{mM}$ L-Glutamine (Sigma-Aldrich, NSW, Australia). For the mineralization assay, the complete $\alpha$-MEM was supplemented with $10 \mathrm{mM}$ glycerophosphate and $50 \mu \mathrm{g} / \mathrm{ml}$ ascorbic acid (Sigma-Aldrich, NSW, Australia) as an osteogenic medium. Cells were maintained in a humidified Heracell 150 incubator (ThermoFisher Scientific ${ }^{\mathrm{TM}}$, IL, USA) at $37^{\circ} \mathrm{C}$ and $5 \% \mathrm{v} / \mathrm{v} \mathrm{CO}_{2}$.

\section{Preparation of CPP-ACP and CPP-ACFP solution}

The soluble CPP-ACP and CPP-ACFP powders (9) were mixed with complete $\alpha$ MEM by magnetic stirring for $24 \mathrm{hrs}$ and sterilized through a $0.22 \mu \mathrm{m}$ filter (Corning Incorporated Life Sciences, MA, USA). Stock solutions of 3.0\% w/v CPP-ACP and 
$3.0 \% \mathrm{w} / \mathrm{v}$ CPP-ACFP were prepared and serially diluted to seven concentrations $(0.05 \%, 0.1 \%, 0.2 \%, 0.3 \%, 0.7 \%, 1.5 \%$ and $3.0 \% \mathrm{w} / \mathrm{v})$

\title{
Cell proliferation and cell cytotoxicity assays
}

Cell proliferation and cell cytotoxicity were assessed using a methyl-thiazoltetrazolium assay kit (MTT, CellTiter $96^{\circledR}$ Aqueous Non-Radioactive Cell Proliferation Assay) and a lactate dehydrogenase assay kit (LDH, CytoTox $96^{\circledR}$ NonRadioactive Cytotoxicity Assay) respectively, according to the manufacturer's instructions (Promega Corporation, WI, USA).

\begin{abstract}
Alkaline phosphatase activity
MG-63 and MC3T3-E1 cell lines were subcultured in 24-well culture plates with complete $\alpha$-MEM $\left(5 \times 10^{4}\right.$ cell/well in $\left.1 \mathrm{ml}\right)$. After $24 \mathrm{~h}$, the culture medium was replaced with $1 \mathrm{ml}$ (per well) of different concentrations of CPP-ACP and CPPACFP-modified medium and incubated for 1, 2 and $3 \mathrm{~d}$. Separate sets of cells for the different groups were used for each time interval. Cells cultured with complete $\alpha$ MEM alone were used as controls. At the end of each incubation period, the cells were washed with phosphate buffered saline (PBS, Sigma-Aldrich, NSW, Australia), $100 \mu \mathrm{l}$ lysis buffer $\left(2.5 \%\right.$ v/v Triton ${ }^{\circledR} \mathrm{X}-114$, Sigma-Aldrich, NSW, Australia) was added to each well and the plates were incubated for $1 \mathrm{~h}$ at room temperature. The cell lysate $(100 \mu \mathrm{l})$ was mixed with $150 \mu \mathrm{l}$ of Quanti-Blue ${ }^{\mathrm{TM}}$ solution and ALP activity measured colorimetrically according to the manufacturer's instructions (InvivoGen, CA, USA). Six replicate samples were measured for each group.
\end{abstract}

\section{Measurement of cytokine production}


To measure human and mouse interleukin-1 $\alpha$ (IL-1 $\alpha$ ) and interleukin-6 (IL-6) production, MG-63, MC3T3-E1, HGF-1 and NIH3T3 cells were subcultured in 24well culture plates with complete $\alpha$-MEM $\left(5 \times 10^{4}\right.$ cell/well in $\left.1 \mathrm{ml}\right)$. After $24 \mathrm{~h}$, the culture medium was replaced with $1 \mathrm{ml}$ (per well) of the different concentrations of CPP-ACP and CPP-ACFP-modified medium and the cells incubated for $3 \mathrm{~d}$. Cells cultured in medium alone were the negative control, and cells cultured in medium with 20 ng/ml Escherichia Coli lipopolysaccharide (LPS, Invitrogen, San Diego, CA, USA) were the positive control. At the end of the incubation period, the supernatant was collected and stored at $-80{ }^{\circ} \mathrm{C}$ until use. The levels of IL- $1 \alpha$ and IL- 6 in the supernatant were measured using a human IL-1 $\alpha$ enzyme-linked immunosorbent assay (ELISA) kit (Abcam Australia Pty Ltd, VIC, Australia), and human IL-6, mouse IL-1 $\alpha$ and mouse IL-6 ELISA kits (eBioscience, CA, USA) according to the manufacturer's instructions. Six replicate samples were tested for each group.

\section{Mineralization measurements}

To assess the role of CPP-ACP and CPP-ACFP in promoting mineralization by osteoblasts, mineralization was induced on confluent MG-63 and MC3T3-E1 cells by the osteogenic media. Cells were subcultured in 6-well culture plates with complete $\alpha$ MEM $\left(2 \times 10^{5}\right.$ cell/well in $\left.4 \mathrm{ml}\right)$. After $48 \mathrm{~h}$, the culture medium was replaced with 4 $\mathrm{ml} / \mathrm{well}$ of CPP-ACP or CPP-ACFP medium $(1.5 \% \mathrm{w} / \mathrm{v}$ and $3.0 \% \mathrm{w} / \mathrm{v} \mathrm{CPP}-\mathrm{ACP}$, and $1.5 \% \mathrm{w} / \mathrm{v}$ and $3.0 \% \mathrm{w} / \mathrm{v}$ CPP-ACFP solutions were tested) and cells incubated for 14

d. Cells cultured with osteogenic media alone were the control. After $14 \mathrm{~d}$ media were collected and stored at $-80^{\circ} \mathrm{C}$ until used for detection of mineralization-associated proteins by immunoblotting and for quantitation of mineralization using the alizarin red (ARS, Sigma-Aldrich, NSW, Australia) method described previously (12). 


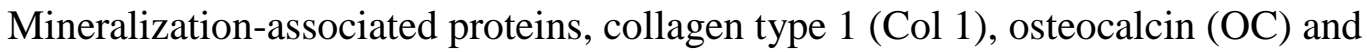
osteopontin (OP) were identified in collected media by immunoblotting using standard techniques. Samples with equal amounts of protein $(40 \mu \mathrm{g})$ measured using the Micro BCA ${ }^{\mathrm{TM}}$ method (ThermoFisher Scientific, IL, USA) were prepared using 4 $\times$ lithium dodecyl sulphate (LDS) sample buffer (Invitrogen, San Diego, CA, USA) and subjected to SDS-PAGE in NuPAGE ${ }^{\circledR}$ MOPS SDS running buffer (Life Technologies, CA, USA) at $200 \mathrm{~V}$ using NuPAGE ${ }^{\circledR} 4-12 \%$ Bis-Tris gels (Life Technologies, CA, USA). Then proteins were transferred (at 42 volt for $1 \mathrm{~h}$ ) in NuPAGE $^{\circledR}$ transfer buffer (Life Technologies, CA, USA) onto a nitrocellulose membrane (PROTRAN ${ }^{\circledR}$, PerkinElmer, MA, USA). The membrane was blocked with $5 \% \mathrm{w} / \mathrm{v}$ skim milk in PBS for $1 \mathrm{~h}$ at room temperature, then washed with PBS and incubated overnight at $4{ }^{\circ} \mathrm{C}$ with primary antibody (rabbit anti-collagen type 1, rabbit anti-osteocalcin or rabbit anti-osteopontin; Abcam Australia Pty Ltd, Victoria, Australia). The membrane was then washed three times with $0.1 \% \mathrm{v} / \mathrm{v}$ tween-20 in PBS (PBST) with gentle agitation for 15 min for each wash, followed by a final wash with PBS alone. After overnight incubation at $4{ }^{\circ} \mathrm{C}$ with goat anti-rabbit IgG HRPconjugated secondary antibody (Sigma-Aldrich, NSW, Australia), the membrane was washed three times in PBST (15 min for each wash) and one wash in PBS. Proteins were detected using Immobilon ${ }^{\mathrm{TM}}$ chemiluminescence reagent (Millipore Corporation, MA, USA) and FUJIFILM LAS-300 camera-based imager (FUJIFILM, Berthold Australia Pty Ltd, Victoria, Australia). To quantify the proteins, densitometry was performed using ImageJ 1.50e (Wayne Rasband, National Institutes of Health, MD, USA).

\section{Statistical analysis}


The data were analyzed using SPSS ver. 11.5.0 (SPSS Inc, IL, USA). The

Kolmogorov-Smirnov (K-S) test indicated that the data were normally distributed and therefore, parametric statistical tests were performed (ANOVA followed by Tukey's test for multiple comparisons). The level of significance was set at $P<0.05$.

\section{Results}

\section{Cell proliferation, cell cytotoxicity and alkaline phosphatase activity}

For the cell lines and CPP-ACP and CPP-ACFP concentrations tested no significant effect on cell proliferation or toxicity could be detected. For both osteoblast-like cell lines CPP-ACP and CPP-ACFP increased alkaline phosphatase (ALP) activity in a dose-related response with two-fold maxima at CPP-ACP/CPP-ACFP concentrations of $0.1 \%$ to $1.5 \%$ w/v (Fig. 1). CPP-ACP/CPP-ACFP did not induce the inflammatory cytokine IL-1 $\alpha$ in any of the cell lines at any of the concentrations tested (data not shown). The secretion of IL-6 from the osteoblast-like cell lines was significantly increased $(P<0.05)$ in a dose-dependent manner when incubated with $0.1 \%-3.0 \%$ w/v CPP-ACP- and $0.05 \%-3.0 \%$ w/v CPP-ACFP-medium when compared with the negative control (Fig. 2). This effect was significantly greater for CPP-ACFP compared with CPP-ACP. For the two fibroblast-like cell lines neither CPP-ACP nor CPP-ACFP had any significant effect on IL-6 production (Fig. 2).

\section{Mineralization and mineralization-related proteins}

The concentration of alizarin red stain extracted from the osteoblast-like MG-63 cells treated with CPP-ACFP-modified osteogenic media were significantly $(P<0.05)$ higher than concentrations of stain extracted from similar cells grown in the control 
and CPP-ACP-modified osteogenic media (Fig. 3). MC3T3-E1 cells grown in the CPP-ACFP and $1.5 \%$ w/v CPP-ACP-modified osteogenic media exhibited significantly higher stain concentrations compared with the control $(P<0.05)$. MC3T3-E1 cells grown in the 3.0\% w/v CPP-ACFP-modified osteogenic media showed the highest stain concentration $(P<0.05)$. CPP-ACP and CPP-ACFP also produced a significant $(P<0.05)$ increase in expression of collagen type $\mathrm{I}(\mathrm{Col} 1)$ and osteocalcin (OC) and a significant decrease in the expression of osteopontin (OP) by the two osteoblast-like cell lines (Fig. 4).

\section{Discussion}

Calcium silicate-based cements have wide application in contemporary endodontics including apexification, perforation repair, vital pulp therapy and regenerative endodontic procedures. However, research continues into improving both their handling properties and biological efficacy (2). The present study introduces a means to further improve the biological properties and has broad clinical relevance in endodontic therapy as demonstrated by the use of both human and mouse cell lines.

CPP-ACP and CPP-ACFP at the concentrations tested were not cytotoxic nor significantly changed proliferation of the osteoblast-like and fibroblast-like cell lines, confirming the biocompatibility of these phosphopeptide-stabilized ionic complexes. CPP-ACP is GRAS certified and previous studies have indicated that the material is biocompatible $(10,13)$. The CPP-ACP and CPP-ACFP dose-related increase in ALP activity (an osteoblastic differentiation marker) expressed by the osteoblast-like cell line correlated with the increased expression of the osteotropic cytokine IL-6, Col 1 and $\mathrm{OC}$ as well as the increased mineral deposition attributable to the addition of 
CPP-ACP/CPP-ACFP. ALP is a non-specific phosphomonoesterase and has a role in

inorganic phosphate (14). The casein phosphopeptides (CPP) contain 5-7

phosphoseryl residues that are phosphoesters and essential for the stabilization of their cargo of calcium and phosphate ions in the ACP ion nanoclusters $(8,15)$. ALP will hydrolyze the phosphoseryl residues of the CPP which will destabilize the ACP nanoclusters resulting in calcification by the precipitation of hydroxyapatite or in the presence of fluoride ions, fluorapatite or fluorhydroxyapatite.

This process is consistent with the increased mineralization observed in the osteoblast-like cell lines on the addition of CPP-ACP/CPP-ACFP in this study. These results are also consistent with a previous investigation demonstrating an increase in ALP activity and the presence of calcified nodules in CPP-Ca treated human osteoblast-like cells (10). CPP have been shown to not only stabilize bioavailable calcium and phosphate ions $(8,15)$ but also induce uptake of $\mathrm{Ca}^{2+}$ and cellular differentiation $(10,11,16)$. Furthermore, $\mathrm{Ca}^{2+}$ is an efficient regulator of several cellular activities such as mineralization and expression of $\mathrm{OC}$ and collagen $(5,17-$ 19). Hence, it is possible that many of the cellular effects of CPP-ACP and CPPACFP may be explained by the significant increase in bioavailable $\mathrm{Ca}^{2+}$ concentration. In order to investigate differentiation of the osteoblast-like MG-63 and MC3T3 cells into mature osteoblasts, cells were cultured for $14 \mathrm{~d}$ in osteogenic media with or without CPP-ACP or CPP-ACFP. In general, exposure of MG-63 and MC3T3-E1 cells to CPP-ACP/CPP-ACFP increased the expression of Col 1 and OC, and decreased the expression of OP. Col 1 is an important factor for the development of a mature osteoblastic phenotype i.e. differentiation and mineralization, and it is the predominant product of osteoblasts, representing $95 \%$ of extracellular non-mineral 
bone matrix $(20,21)$. The expression of $\mathrm{OC}$, a bone-specific protein and marker of osteogenic maturation, occurs subsequent to initiation of ALP activity and accompanies mineralized tissue formation $(22,23)$. Col 1 together with OC contribute to the initiation of nucleation and hierarchical assembly of apatite within the collagen scaffold, a critical process in bone formation (24). The increase in mineralization and increased expression of Co1 and OC by exposure of osteoblast-like cells to CPPACP/CPP-ACFP observed in this study are consistent with this proposed mechanism of mineralization initiation. OP is not detected with bone formation, as its synthesis is closely associated with initiation and mediation of bone resorption (25). OP, a strong inhibitor of the mineralization process, has the ability to bind to apatite crystals inhibiting their growth (26). As such, the decrease in expression of OP and increase of Col 1 and OC shown in this study supports CPP-ACP and CPP-ACFP favoring bone formation.

IL-1 cytokines are responsible for the production of sterile inflammation (27). However, there was no evidence that neither CPP-ACP nor CPP-ACFP triggered an inflammatory response in the osteoblast-like and fibroblast-like cell lines, as no IL-1 $\alpha$ could be detected. This is consistent with the known biocompatibility of these nanocomplexes. The production of IL- 6 by the osteoblast-like cell lines was significantly increased by incubation with CPP-ACP and CPP-ACFP media. Although IL-6 is believed to be an osteolytic factor (28), it has an important role in osteoblastic differentiation by enhancing ALP activity $(29,30)$. IL-6 is produced by osteoblasts stimulated by growth factors, and it has a role in osteoclast formation and recruitment important for reparative and physiologic bone remodeling $(31,32)$. IL-6 also plays a role in osteoblast formation in situations of high bone turnover (33). Calciumenriched CPP has been reported to act as a modulator of the intestinal immune system 
triggering cytokine secretion such as IL-6, attributed to elevated levels of $\mathrm{Ca}^{2+}(34$, 35). Therefore, taken together the most likely explanation for the present findings is that CPP-ACP and CPP-ACFP provided an elevated bioavailable $\mathrm{Ca}^{2+}$ concentration which triggered production of IL-6, subsequently inducing ALP activity, osteoblastic differentiation and mineralization. The differences between CPP-ACP and CPP-ACFP in inducing mineralization and secretion of IL-6, Col 1 and OC may be attributable to the superior mineralization potential of CPP-ACFP (9).

\section{Conclusion}

Both CPP-ACP and CPP-ACFP are biocompatible with the potential to induce osteoblastic differentiation and calcification/mineralization. These findings may support the use of these materials as bioactive additives to endodontic cements to promote hard tissue regeneration as well as a calcification barrier in vital pulp therapy. Further research is indicated to directly compare calcium silicate based materials with and without the addition of CPP-ACP or CPP-ACFP. 


\section{Figure Legends}

Figure 1. Effect of CPP-ACP(F) on the production of ALP activity by the osteoblastlike cell lines MG-63 and MC3T3-E1. $\square$ CPP-ACP $\|$ CPP-ACFP. *denotes significant differences $(P<0.05)$ compared with controls (cells in medium alone).

Figure 2. Effect of CPP-ACP(F) on the production of the osteotropic cytokine IL-6 by the osteoblast-like cell lines (MG-6 and MC3T3-E1) and fibroblast-like cell lines (HGF-1 and NIH3T3). $\square$ CPP-ACP $\square$ CPP-ACFP. The positive control represents cells exposed to E.coli LPS. *Denotes significant differences $(P<0.05)$ compared with the negative control (cells in medium alone).

Figure 3. (A): Alizarin red stained human and mouse osteoblast-like [MG-63 (a to e) and MC3T3-E1 (f to j)] cells after treatment with osteogenic media with and without CPP-ACP and CPP-ACFP. (a) and (f) Control media, (b) and (g) 1.5\% w/v CPPACP-modified media, (c) and (h) 3.0\% w/v CPP-ACP-modified media, (d) and (i) $1.5 \%$ w/v CPP-ACFP-modified media, (e) and (j) $3.0 \%$ w/v CPP-ACFP-modified media. (B): Concentration (optical density at $405 \mathrm{~nm}$ ) of alizarin red stain extracted from the treated cells.

$\square$ Control, $\square 1.5 \%$ CPP-ACP, $103 \%$ CPP-ACP, $\boxminus 1.5 \%$ CPP-ACFP, $3 \%$ CPP-ACFP. *Denotes significant differences compared with control group i.e. osteogenic media alone $(P<0.05)$.

Figure 4. (A): Secretion of mineralization-related proteins (Collagen I; Col I, Osteopontin; OP and Osteocalcin; OC) from human and mouse osteoblast-like cells 
after exposure to CPP-ACP and CPP-ACFP modified osteogenic media. (B):

Percentage of mineralization-related proteins (relative to control) secreted from human and mouse osteoblast-like cells after exposure to CPP-ACP and CPP-ACFP modified osteogenic media. $\square$ Control, $\square$ 1.5\% CPP-ACP, 1 3\% CPP-ACP, $\boxminus$ $1.5 \%$ CPP-ACFP, 3\% CPP-ACFP. *Denotes significant differences compared with control. 


\section{References}

1. Dawood AE, Manton DJ, Parashos P, et al. The physical properties and ion $\underline{\text { release of CPP-ACP-modified calcium silicate-based cements. Aust Dent J }}$ 2015;60:434-44.

2. Cintra LTA, Benetti F, de Azevedo Queiroz IO, et al. Cytotoxicity, biocompatibility, and biomineralization of the new high-plasticity MTA material. J Endod 2017;43:774-78.

3. Rashid F, Shiba H, Mizuno N, et al. The effect of extracellular calcium ion on gene expression of bone-related proteins in human pulp cells. J Endod 2003;29:104-7.

4. Tada H, Nemoto E, Kanaya S, et al. Elevated extracellular calcium increases expression of bone morphogenetic protein-2 gene via a calcium channel and ERK pathway in human dental pulp cells. Biochem Biophys Res Commun 2010;394:1093-97.

5. Gabusi E, Manferdini C, Grassi F, et al. Extracellular calcium chronically induced human osteoblasts effects: specific modulation of osteocalcin and collagen type XV. J Cell Physiol 2012;227:3151-61.

6. Sangwan P, Sangwan A, Duhan J, et al. Tertiary dentinogenesis with calcium hydroxide: a review of proposed mechanisms. Int Endod J 2013;46:3-19.

7. Fitzgerald M, Chiego DJ, Heys DR. Autoradiographic analysis of odontoblast replacement following pulp exposure in primate teeth. Arch Oral Biol $1990 ; 35: 707-15$. 
8. Reynolds EC. Anticariogenic complexes of amorphous calcium phosphate stabilized by casein phosphopeptides: a review. Spec Care Dentist 1998;18:816.

9. Cochrane NJ, Saranathan S, Cai F, et al. Enamel subsurface lesion remineralisation with casein phosphopeptide stabilised solutions of calcium, phosphate and fluoride. Caries Res 2008;42:88-97.

10. Donida BM, Mrak E, Gravaghi C, et al. Casein phosphopeptides promote calcium uptake and modulate the differentiation pathway in human primary osteoblast-like cells. Peptides 2009;30:2233-41.

11. Tulipano G, Bulgari O, Chessa S, et al. Direct effects of casein phosphopeptides on growth and differentiation of in vitro cultured osteoblastic cells (MC3T3E1). Regul Pept 2010;160:168-74.

12. Gregory CA, Grady Gunn W, Peister A, et al. An Alizarin red-based assay of mineralization by adherent cells in culture: comparison with cetylpyridinium chloride extraction. Anal Biochem 2004;329:77-84.

13. Cehreli SB, Gurpinar AO, Onur AM, et al. In vitro evaluation of casein phosphopeptide-amorphous calcium phosphate as a potential tooth transport medium: viability and apoptosis in L929 fibroblasts. Dent Traumatol 2008;24:314-19.

14. Golub EE, Boesze-Battaglia K. The role of alkaline phosphatase in mineralization. Curr Opin Orthop 2007;18:444-48. 
15. Reynolds EC. Remineralization of enamel subsurface lesions by casein phosphopeptide-stabilized calcium phosphate solutions. J Dent Res 1997;76:1587-95.

16. Cosentino S, Gravaghi C, Donetti E, et al. Caseinphosphopeptide-induced calcium uptake in human intestinal cell lines HT-29 and Caco2 is correlated to cellular differentiation. J Nutr Biochem 2010;21:247-54.

17. Kulesz-Martin MF, Fabian D, Bertram JS. Differential calcium requirements for growth of mouse skin epithelial and fibroblast cells. Cell Tissue Kinet $1984 ; 17: 525-33$.

18. Torneck CD, Moe H, Howley TP. The effect of calcium hydroxide on porcine pulp fibroblasts in vitro. J Endod 1983;9:131-6.

19. Zayzafoon M. Calcium/calmodulin signaling controls osteoblast growth and differentiation. J Cell Biochem 2006;97:56-70.

20. Shi S, Kirk M, Kahn AJ. The role of type I collagen in the regulation of the osteoblast phenotype. J Bone Miner Res 1996;11:1139-45.

21. Lynch MP, Stein JL, Stein GS, et al. The influence of type I collagen on the development and maintenance of the osteoblast phenotype in primary and passaged rat calvarial osteoblasts: modification of expression of genes supporting cell growth, adhesion, and extracellular matrix mineralization. Exp Cell Res 1995;216:35-45. 
22. Aronow MA, Gerstenfeld LC, Owen TA, et al. Factors that promote progressive development of the osteoblast phenotype in cultured fetal rat calvaria cells. J Cell Physiol 1990;143:213-21.

23. Nakamura A, Dohi Y, Akahane M, et al. Osteocalcin secretion as an early marker of in vitro osteogenic differentiation of rat mesenchymal stem cells. Tissue Eng Part C Methods 2009;15:169-80.

24. Weiner S. Biomineralization: a structural perspective. J Struct Biol 2008;163:229-34.

25. Arai N, Ohya K, Ogura H. Osteopontin mRNA expression during bone resorption: An in situ hybridization study of induced ectopic bone in the rat. Bone Miner 1993;22:129-45.

26. Pampena DA, Robertson KA, Litvinova O, et al. Inhibition of hydroxyapatite formation by osteopontin phosphopeptides. Biochem J 2004;378:1083-87.

27. Lukens JR, Gross JM, Kanneganti TD. IL-1 family cytokines trigger sterile inflammatory disease. Front Immunol 2012;3:315.

28. de la Mata J, Uy HL, Guise TA, et al. Interleukin-6 enhances hypercalcemia and bone resorption mediated by parathyroid hormone-related protein in vivo. J Clin Invest 1995;95:2846-52.

29. Nishimura R, Moriyama K, Yasukawa K, et al. Combination of interleukin-6 and soluble interleukin- 6 receptors induces differentiation and activation of JAK-STAT and MAP kinase pathways in MG-63 human osteoblastic cells. J Bone Miner Res 1998;13:777-85. 
30. Iwasaki K, Komaki M, Mimori K, et al. IL-6 induces osteoblastic differentiation of periodontal ligament cells. J Dent Res 2008;87:937-42.

31. Franchimont N, Canalis E. Platelet-derived growth factor stimulates the synthesis of interleukin-6 in cells of the osteoblast lineage. Endocrinology $1995 ; 136: 5469-75$

32. Kidd LJ, Stephens AS, Kuliwaba JS, et al. Temporal pattern of gene expression and histology of stress fracture healing. Bone 2010;46:369-78.

33. Franchimont N, Wertz S, Malaise M. Interleukin-6: An osteotropic factor influencing bone formation? Bone 2005;37:601-06.

34. Kitts DD, Nakamura S. Calcium-enriched casein phosphopeptide stimulates release of IL-6 cytokine in human epithelial intestinal cell line. J Dairy Res 2006;73:44-8.

35. Veronesi B, Carter JD, Devlin RB, et al. Neuropeptides and capsaicin stimulate the release of inflammatory cytokines in a human bronchial epithelial cell line. Neuropeptides 1999;33:447-56. 
Figure 1

Click here to download high resolution image

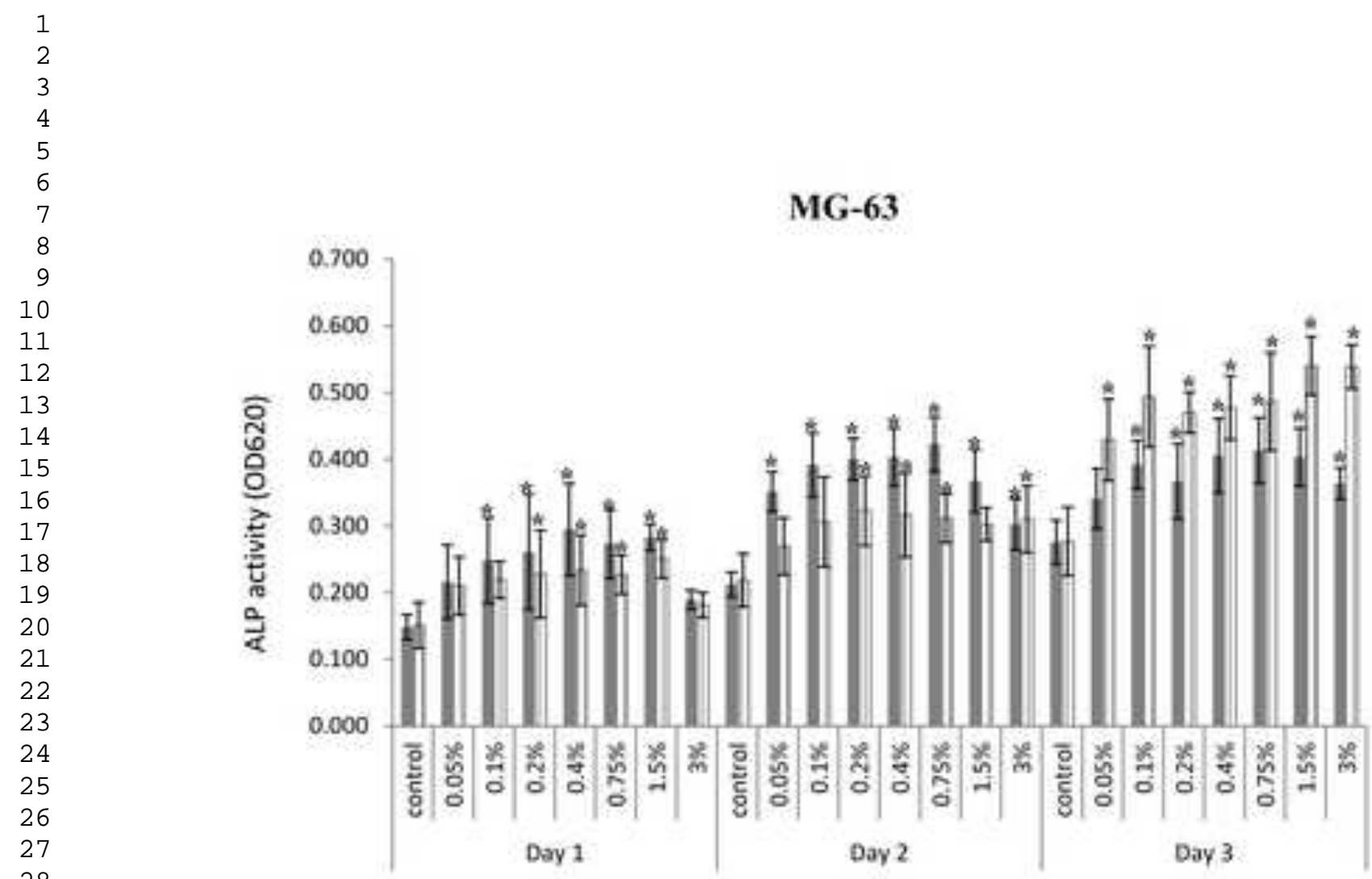

MC3T3-E1

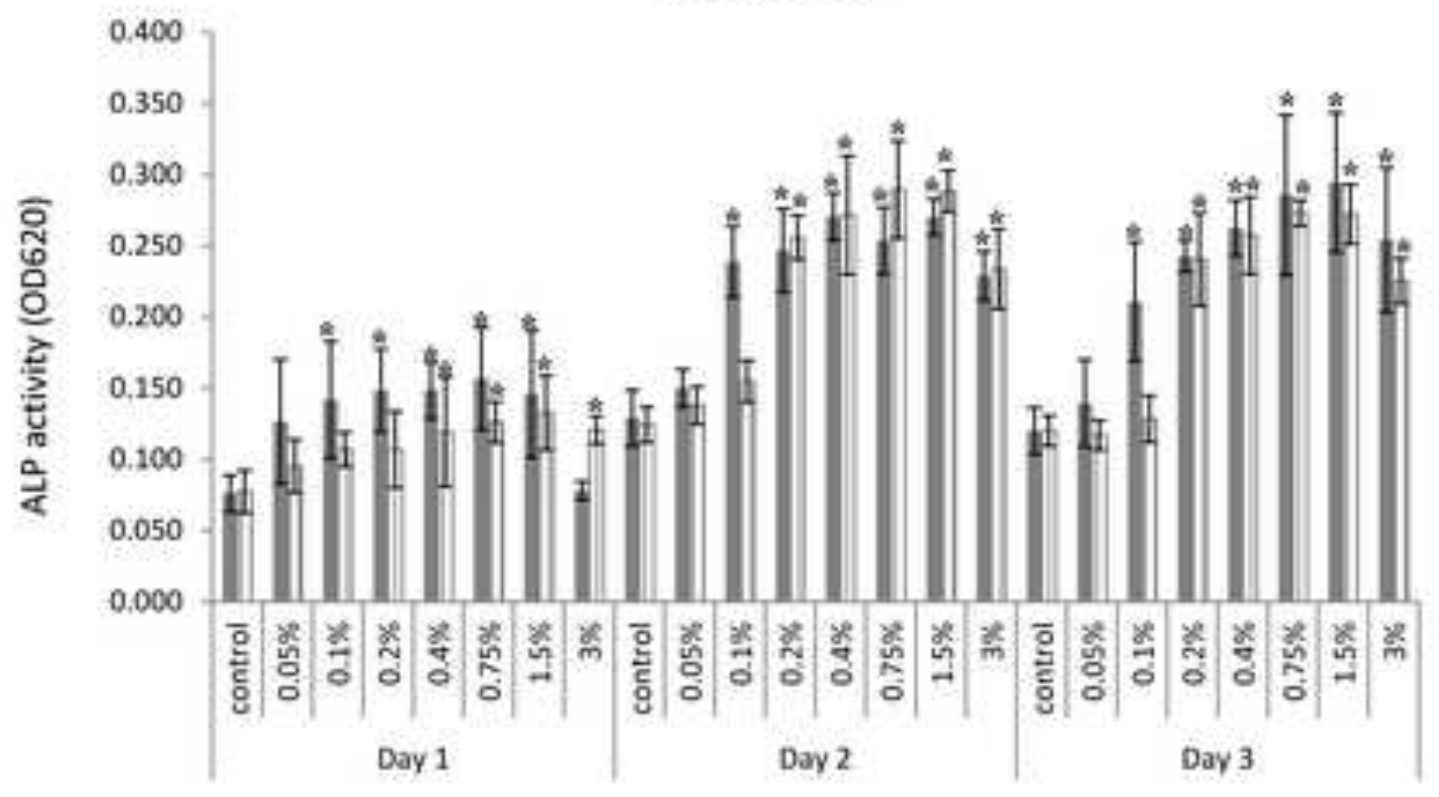


MG-63

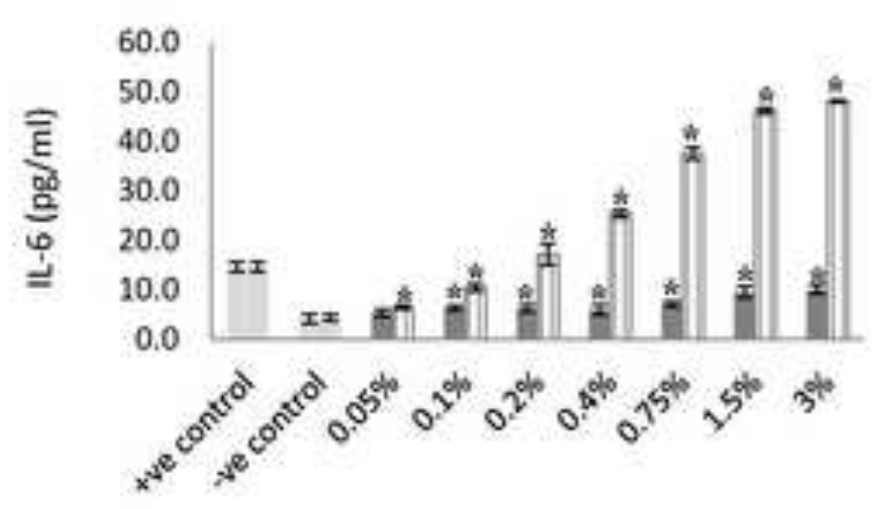

HGF-1

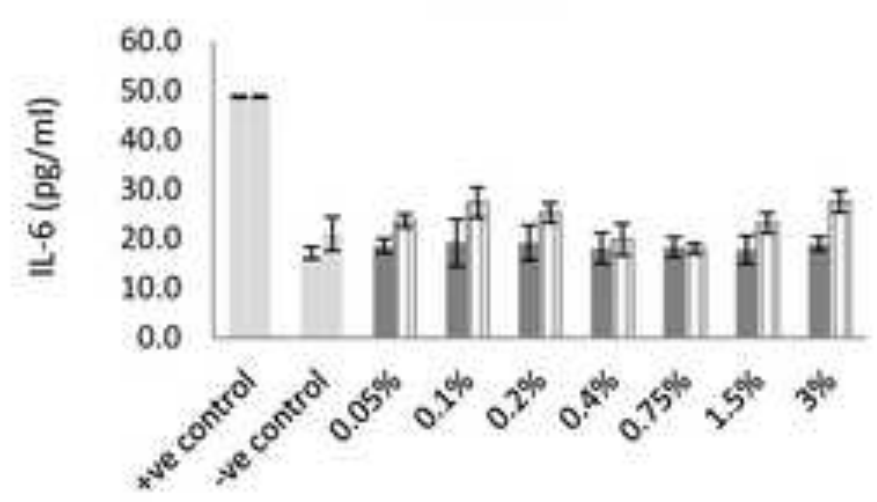

MC3T3-E1

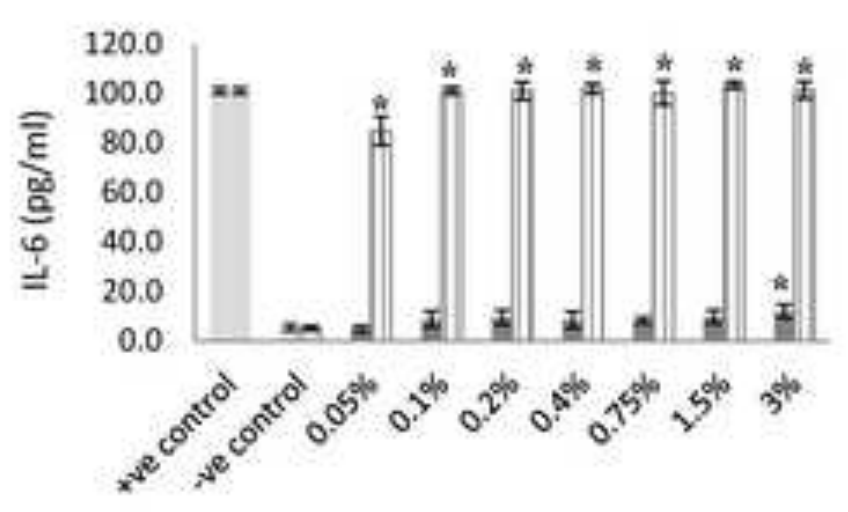

NIH 3T3

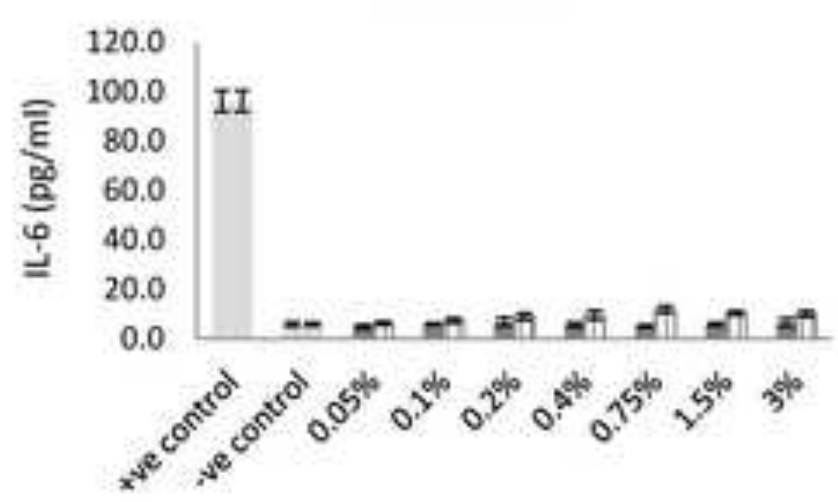


Figure 3
Click here to download high resolution image

(A)
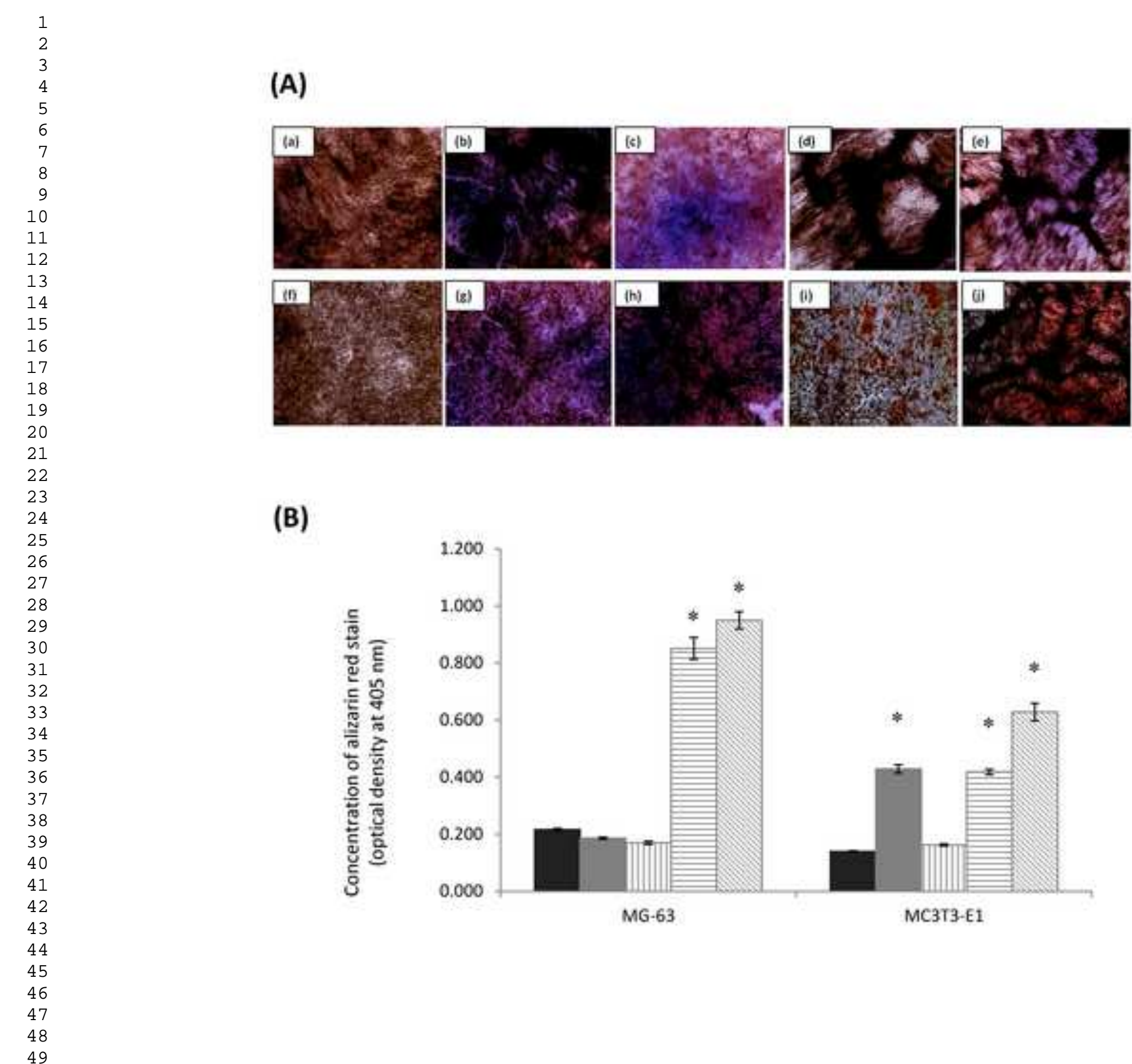

(B)

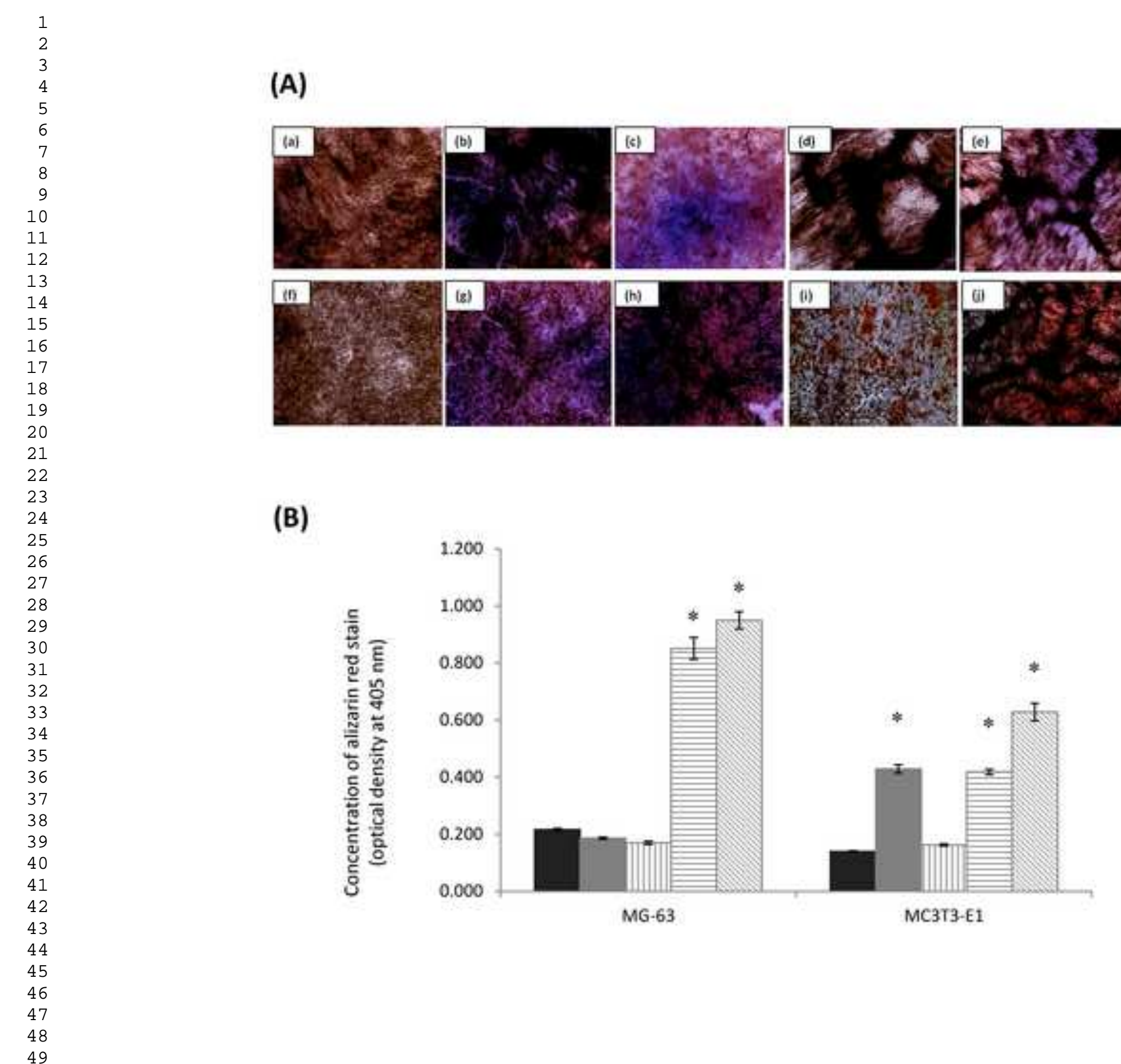

Figure 3
Click here to download high resolution imag

1
2
3
4
5
6
7
8
9
10
11
12
13
14
15
16
17
18
19
20
21
22
23
24
25
26
27
28
29
30
31
32
33
34
35
36
37
38
39
40
41
42
43
44
45
46
47
48
49

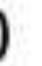

28
29
30
31
32
33
34
35
36
37
38
39
40
41

4

46

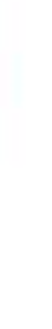


Click here to download high resolution image

(A)

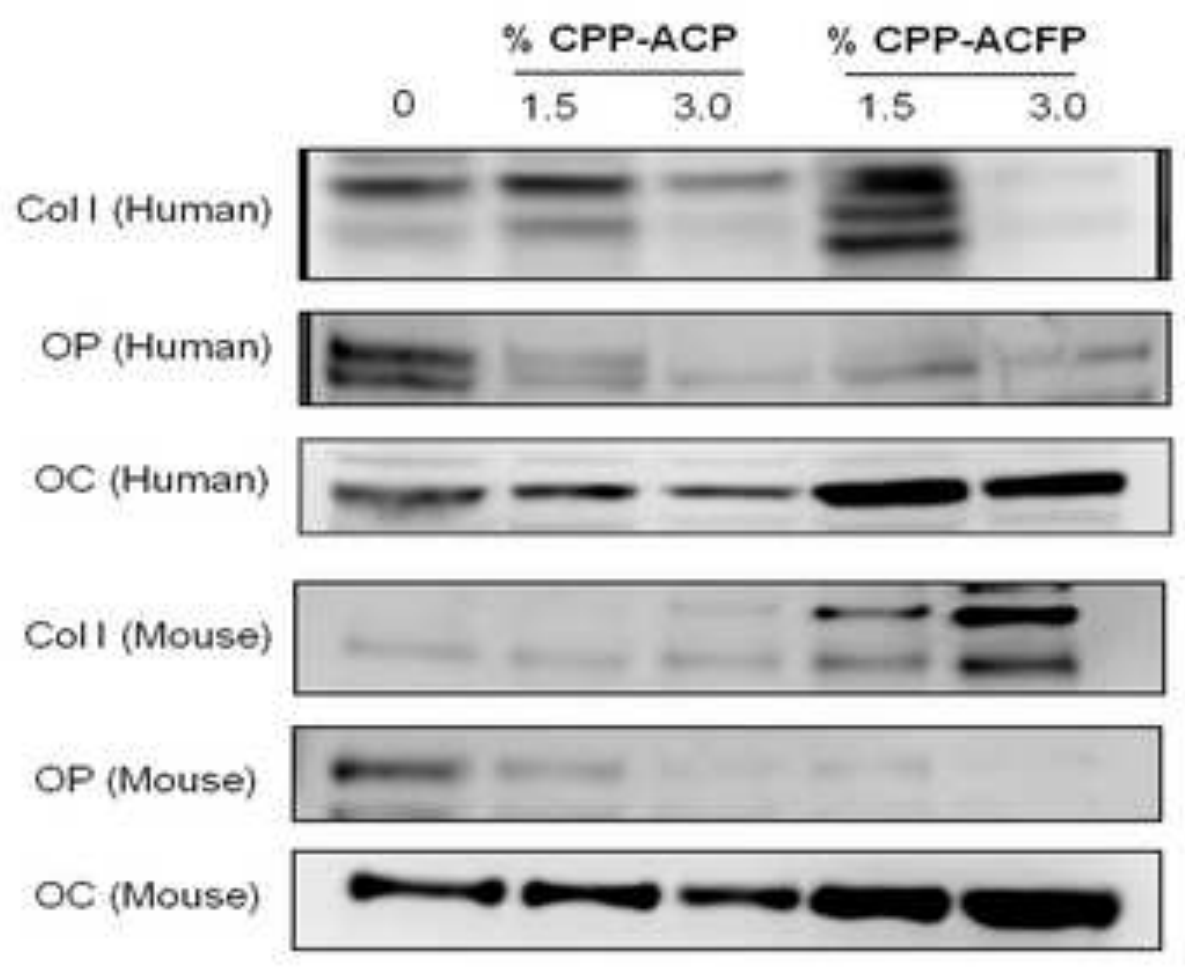

(B)

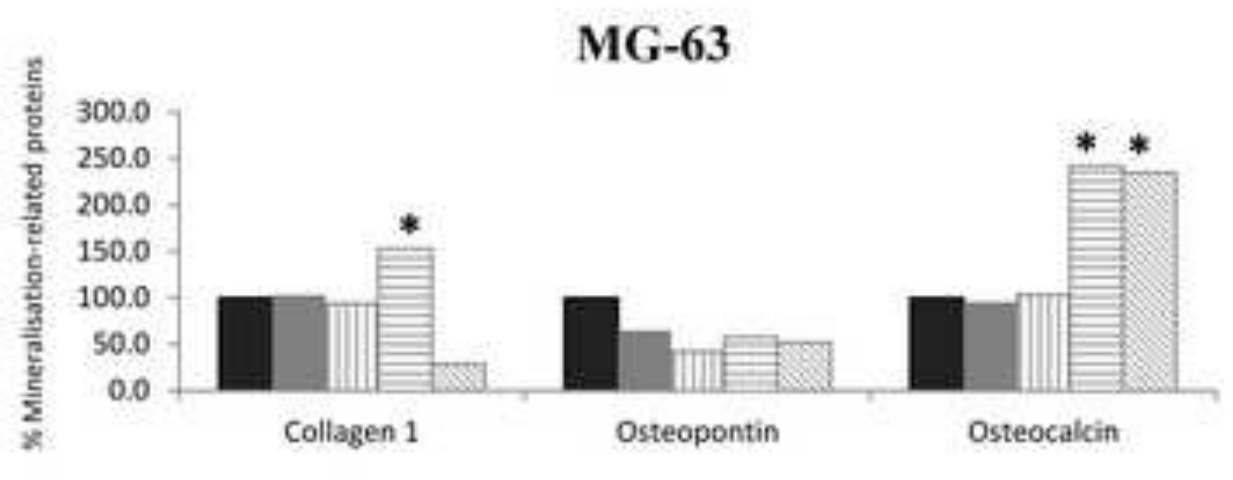

\section{MC3T3-E1}

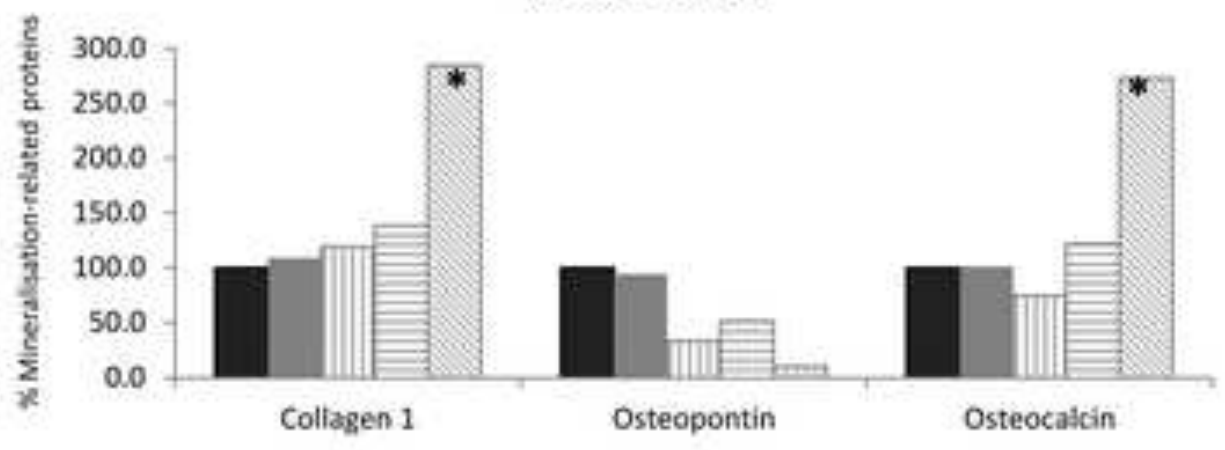

